\title{
Uma voz de imbondeiro no silêncio da gravana: a representação da mulher na poesia de Alda Espírito Santo e Conceição Lima
}

\author{
Érica Antunes ${ }^{1}$
}

RESUMO: Alda Espírito Santo e Conceição Lima são as poetas que melhor representam a literatura são-tomense de autoria feminina e, embora pertençam a gerações diferentes, suas obras se aproximam tanto pela abordagem temática, quanto pelo projeto de busca por uma identidade feminina. Neste trabalho, partindo de dois poemas que dialogam entre si "Às mulheres da minha terra", de Alda Espírito Santo, e "Gravana", de Conceição Lima -, pretendemos analisar de que forma a mulher, portadora de uma voz aparentemente silenciosa e marcada pelo cotidiano, consegue se inscrever no espaço social e, ao mesmo tempo, transformá-lo.

ABSTRACT: Alda Espírito Santo and Conceição Lima are two poets from São Tomé e Príncipe. Although belonging to different generations, they are the ones who best represent the São-Tomense literature of feminine authorship. Their works come closely both by thematic approach and by the search project for a feminine identity. In this paper, based on two poems that dialog with each other - "As mulheres de minha terra", by Alda Espírito Santo, and "Gravana", by Conceição Lima - , we intend to analyze in what way the woman, holder of an apparently silent voice and marked by the daily routine, can enroll in the social space by changing it at the same time.

PALAVRAS-CHAVE: literaturas africanas de língua portuguesa; poesia sãotomense; representação da mulher.

KEYWORDS: African literature of Portuguese language; poetry of São Tomé e Príncipe; woman's representation.

1 Doutoranda em Estudos Comparados de Literaturas de Língua Portuguesa na Universidade de São Paulo (USP) e bolsista da Fundação de Amparo à Pesquisa do Estado de São Paulo (FAPESP). Pesquisa: Da catana ao batom: a construção da identidade feminina nas poesias angolana, moçambicana e são-tomense. E-mail: erica.antunes@gmail.com. 
Gosto de pensar no sentido da palavra "conversante" quando leio os poemas de Alda Espírito Santo e Conceição Lima: a primeira, nascida em 1926, lutou de modo ativo em prol da independência de São Tomé e Príncipe e lançou à terra a semente que mais tarde seria regada pela segunda, trinta e cinco anos mais jovem, já em seu livro de estréia. Assim, ainda que oriundas de gerações distintas e sendo resguardadas as características estéticas de suas produções, observo certa correspondência temática na poesia de ambas: os poemas "conversam" entre si e instauram uma idéia de dinamicidade que o sufixo "ante" - de “conversante" - traduz com muita eficácia.

Um dos temas caros às autoras é o silêncio, bem como o seu rompimento, dando passagem a um canto que denuncia uma situação e reivindica que, de alguma forma, ela seja modificada. Levando em conta que minha pesquisa de doutorado focaliza representação da mulher e a formação da identidade feminina na poesia angolana, moçambicana e são-tomense, procurarei, nesta apresentação, analisar de que modo ela, a mulher, portadora de uma voz marcada pelo cotidiano, consegue se inscrever no espaço social e até transformá-lo. Para tanto, escolhi os poemas "Às mulheres da minha terra”, de Alda Espírito Santo (1978, p. 81-85), e "Gravana”, de Conceição Lima (p. 50-51), os quais passo agora a invocar.

Em primeiro lugar, ouçamos o poema de Alda Espírito Santo:

Irmãs, do meu torrão pequeno Que passais pela estrada do meu país de África É para vós, irmãs, a minha alma toda inteira - Há em mim uma lacuna amarga -

Eu queria falar convosco no nosso crioulo cantante Queria levar até vós, a mensagem das nossas vidas Na língua maternal, bebida com o leite dos nossos primeiros dias Mas irmãs, vou buscar um idioma emprestado Para mostrar-vos a nossa terra O nosso grande continente, Duma ponta a outra. Queria descer convosco às nossas praias Onde arrastais as gibas da beira-mar Sentar-me, na esteira das nossas casas, Contar convosco os dez mil réis Do caroço vendido Na loja mais próxima, Do vinho de palma 
Regateado pelos caminhos,

Do andim vendido à pinha,

Às primeiras horas do dia.

Queria também

Conversar com as lavadeiras dos nossos rios

Sobre a roupa de cada dia

Sobre a saúde dos nossos filhos

Roídos pela febre

Calcurreando léguas a caminho da escola.

Irmã, a nossa conversa é longa.

É longa a nossa conversa.

Através destes séculos

De servidão e miséria...

É longa a estrada do nosso penar.

Nossos pés descalços

Estão cansados de tanta labuta...

O dinheiro não chega

Para vencer a nossa fome

Dos nossos filhos

Sem trabalho

Engolindo a banana sem peixe

De muitos dias de penúria.

Não vamos mais fazer "nozados" longos

Nem lançar ao mar

Nas festas de Santos sem nome

A saúde das nossas belas crianças,

A esperança da nossa terra.

Uma conversa longa, irmãs.

Vamos juntar as nossas mãos

Calosas de partir caroço

Sujas de banana

"Fermentada" no "macucu"

Na nossa cozinha

De "vá plegá”...

A nossa terra é linda, amigas

E nós queremos

Que ela seja grande...

Ao longo dos tempos!...

Mas é preciso, Irmãs

Conquistar as Ilhas inteiras

De lés a lés.

Amigas, as nossas mãos juntas, As nossas mãos negras

Prendendo os nossos sonhos estéreis

Varrendo com fúria

Com a fúria das nossas "palayês"

Das nossas feiras,

As coisas más da nossa vida.

Mas é preciso conversar

Ao longo dos caminhos.

Tu e eu minha irmã.

É preciso entender o nosso falar Juntas de mãos dadas, 
Vamos fazer a nossa festa...!

A festa descerá

Ao longo de todas as vilas

Agitará as palmeiras mais gigantes

E terá uma força grande

Pois estaremos juntas irmãs

Juntas na vida

Da nossa terra

Mas é preciso conhecer

A razão das nossas secretas angústias.

Procurar vencer Irmãs

A fúria do rio

Em dias de tornado

Saber a razão

Encontrar a razão de tudo...

"Os nossos filhos

O nosso filho morreu

Roído pela febre”...

Muitos pequeninos

Morrem todos os dias

Vencidos pela febre

Vencidos pela vida...

Não gritaremos mais

os nossos cânticos dolorosos

Prenhes de eterna resignação...

Outro canto se elevará Irmãs,

Por cima das nossas cabeças.

Vamos procurar a razão.

A hora das nossas razões vencidas

Se avizinha.

A hora da nossa conversa

Vai ser longa.

De roda do caroço

De roda das cartas

escritas por outrém,

Porque a fome é grande

E nós não sabemos ler.

Não sabemos ler, irmãs

Mas vamos vencer o medo.

Vamos vencer nosso medo

De sermos sós na terra imensa.

Jamais estaremos solitárias...

Porque a nossa força há-de crescer.

E então conquistaremos

para nós

para os filhos gerados no nosso ventre,

Nas nossas horas de Angústia

- Para nós -

A nossa bela terra

No dia que se avizinha

Saindo das nossas bocas,

Uma palavra bela

Bela e silenciosa

A palavra mais bela

Ciciada no nosso crioulo,

A palavra sem nome

Entoada no silêncio 
Num coro gigante

Correndo ao longo das nossas cascatas,

Das cachoeiras mais distantes,

O canto do silêncio, Irmãs

Há-de soar

Quando chegar a Gravana.

E por hoje, Irmãs

Aguardemos a gravana

Ao longo das nossas conversas

No serão das nossas casas

sem nome.

Já o título do poema - "Às mulheres da minha terra" - traz algumas informações importantes: tomada em primeira pessoa, a palavra será dirigida "às mulheres" que, por sua vez, pertencem a um local específico - "a minha [do sujeito poético] terra" -, sinalizando para a identidade nacional e feminina que provavelmente restará comprovada no decorrer dos versos. A crase contida no título retira qualquer caráter descritivo e abre caminho para a interlocução, inaugurada com o vocativo logo no primeiro verso. Somando-se a isso o fato de a estrutura do poema ser composta de versos livres e cujo conteúdo semelha, de fato, uma "conversa", não é difícil constatar que estamos diante de um poema em prosa.

Ao tratar as mulheres por "irmãs", o sujeito poético se põe em pé de igualdade, o que é acentuado pela vontade de falar com elas em "crioulo cantante", levando-lhes a "mensagem das vidas/ $\mathrm{Na}$ língua maternal", ainda que seja obrigado a "buscar um idioma emprestado" para mostrar-lhes a terra e, por conta disso, sentir sobre si uma "lacuna amarga". Mais: neste caso, se o idioma é emprestado, não é difícil constatar que estamos diante de um sujeito poético que se posiciona a partir do ponto de vista do colonizado.

Na seqüência, o sujeito poético realça o desejo de manter uma ligação próxima com as mulheres de sua terra, seja durante o caminho para a praia, a feitura da quitanda ou em conversas cotidianas "Sobre a roupa de cada dia/ Sobre a saúde dos nossos filhos/ Roídos pela febre/ Calcurreando léguas a caminho da escola.”

É nesse ponto que se abre a segunda estrofe e o sujeito poético, baseado em imagens também do dia-a-dia, anuncia a necessidade de 
uma “conversa longa”, já (d)enunciando os problemas enfrentados pela mulher na sociedade são-tomense: "O dinheiro não chega/ Para vencer a nossa fome/ Dos nossos filhos/ Sem trabalho/ Engolindo a banana sem peixe/ De muitos dias de penúria."

Desta forma, instaura-se, no poema, um clima de mudança: o sujeito poético instiga as mulheres a se unirem - o que faz também se valendo de imagens da faina diária, como o ato de partir o caroço, ou mesmo graças ao uso reiterado do pronome possessivo na primeira pessoa do plural - para lutar pela própria terra, uma "terra [que] é linda”. Em outras palavras, há a inclusão de todas essas mulheres à causa por que milita o sujeito poético, quando este diz: "E nós queremos que ela [a terra] seja grande.../ Ao longo dos tempos!..." e, por isso, "é preciso, Irmãs/ Conquistar as Ilhas inteiras/ De lés a lés.", numa evidente referência à luta pela libertação nacional, posto São Tomé e Príncipe ser, na época, uma colônia portuguesa. É assim que o sujeito poético passa a se valer de várias metáforas da união, como a das “mãos juntas” e, mais ainda, o "falar/ Juntas de mãos dadas” e “Juntas na vida”, rompendo o silêncio em relação à colônia e marcando o início do processo pela busca da identidade nacional. Mas não é só: essas imagens indicam também o rompimento do silêncio feminino, de modo que as mulheres, tidas até então como seres duplamente colonizados, passam a reivindicar seu espaço social e político para, um dia, "fazer[em] a nossa [sua] festa...!", uma festa que "descerá/ Ao longo de todas as vilas/ Agitará as palmeiras mais gigantes/ E terá uma força grande".

Ainda nessa senda, o sujeito poético, ao invocar a "fúria do rio", alerta as mulheres sobre a necessidade de persistência, paciência e, sobretudo, de força, muita força para enfrentar as adversidades que surgirem e não gritarem "mais/ os nossos cânticos dolorosos/ Prenhes de eterna resignação...”. Assim, para que o êxito seja alcançado, são necessários união e compromisso entre as mulheres; estas, uma vez capazes de gerar, devem também ser hábeis para regar a vida por meio de um canto/conversa que se eleva em busca da "razão". Tais 
elementos conduzem a uma antilogia, pois conforme "Uma palavra bela/ Bela e silenciosa/ A palavra mais bela/ Ciciada no nosso crioulo" é "Entoada no silêncio/ Num coro gigante", traduzindo "O canto do silêncio" que "Há-de soar/ Quando chegar a Gravana." ${ }^{2}$, verifica-se toda uma carga contestatória, levando em conta que "silenciar é dizer por outra via - já que o silêncio potencia o que ali luz, presente, pelo fulgor mesmo de sua ausência.” (HOLANDA, 1992, p. 17)

Esse mesmo percurso do silêncio à voz é encontrado no poema “conversante" intitulado "Gravana" (2004, p. 50-51), escrito por Conceição Lima e dedicado a Alda Espírito Santo. Ouçamos:

\author{
Na nossa terra, amiga, há um tempo \\ de silêncio e caules ressequidos \\ Chega com metacarpos definhados \\ quando na úbua desfalece a trepadeira \\ Entra com o bafo poeirento \\ rarefeitas as unhas, candrezados os ramos \\ e ulula de mansinho nos bananais \\ como um melancólico aviso \\ É um tempo de folhas sem orvalho e mem-lôfi \\ de pagauês doridos, carentes de leite \\ de soturna claridade ao pôr do sol \\ A fria brisa nos diz que esse tempo virá \\ E cobertas de pó \\ ficarão as hastes do pilincano \\ imoladas ao hálito da terra \\ Será triste o rio e seu nome \\ na lonjura do vági \\ mortas estarão as casas e suas janelas \\ morto o suim-suim e seu canto \\ morto o macucú e a ubaga velha \\ A pele de pitangueiras e salambás beberá \\ das frutas torrenciais a lembrança \\ porque o luchan estará morto \\ amiga \\ Mas sobre a pedra e o fogo
}

2 No glossário de É nosso o solo sagrado, obra de Alda Espírito Santo, a gravana é definida como "estação fresca"; no entanto, creio ter havido um equívoco, de modo que me parece correta a explicação constante da obra A dolorosa raiz do micondó, de Conceição Lima, que prevê a gravana como sinônimo de "estação seca". 
tua voz de imbondeiro crescerá do barro para resgatar a praça em nova festa

para ressuscitar o povo e sua gesta.

Valendo-se, entre outros, de elementos típicos da fauna e da flora são-tomense, o sujeito poético confirma que o projeto de busca pela identidade nacional semeado em “Às mulheres da minha terra” já está germinando, ou seja, há uma resposta positiva ao chamamento das mulheres, que se posicionam social e politicamente. Tanto isso é crível que o vocativo empregado logo no primeiro verso de "Gravana" é "amiga" e indicia, de plano, uma interlocução com o sujeito poético do poema de Alda Espírito Santo.

O tempo verbal empregado em "Gravana" oscila entre o presente e o futuro, o que também confirma a idéia do comprometimento feminino desde a invocação havida em "Às mulheres da minha terra". Melhor explicando, quando o sujeito poético afirma que "há um tempo/ de silêncio e caules ressequidos, está ratificando o que foi, há muitos anos, previsto; no entanto, o adjunto adnominal conduz a um determinado período que até pode se alastrar um pouco, mas continua marcado pela finitude e pela possibilidade de uma situação ser revertida.

As imagens, ao longo de todo o poema, são caracterizadas pela rudeza e pela seca: são "caules ressequidos", "metacarpos definhados", "bafo poeirento", "candrezados os ramos”, "folhas sem orvalho" e pó nas "hastes do pilincano", tudo levando a crer na impossibilidade de germinação da semente, ainda que este tenha sido plantada com extremo empenho, como no caso de "Às mulheres da minha terra". Essa idéia é ainda reforçada por outra série de imagens condutoras de desolamento, como o silêncio, o desfalecimento da trepadeira, a rarefação das unhas, a "soturna claridade ao pôr do sol", a "fria brisa", o "triste rio", e também pela anáfora presente na sétima estrofe: "mortas estarão as casas e suas janelas / morto o suim-suim e seu canto/ morto o macucú e a ubaga velha”. Assim é que, na oitava estrofe, o sujeito poético fecha esse ciclo e afirma que, com tamanha carga de 
sentimentos/acontecimentos negativos, "o luchan estará morto", só dele restando a lembrança, a memória.

Mas não é isso o que acontece na verdade, pois o vocativo, indicador da conversa entre os sujeitos poéticos dos dois poemas, aliado a uma conjunção adversativa que dá início à última estrofe, constitui a estratégia empregada para o resgate da esperança; assim, "sobre a pedra e o fogo/ tua voz de imbondeiro crescerá do barro/ para resgatar a praça em nova festa/ para ressuscitar o povo e sua gesta.". Logo, a pedra e o fogo, que tanto podem significar o dado quanto o construído, parecem se ligar à tradição e, a partir do barro moldado sobre tais elementos, germina uma "voz de imbondeiro"; tal qual a árvore, esta é longeva, sagrada e simboliza a força e a tranqüilidade de uma praça/país que, agora sim, como ansiava o poema de Alda Espírito Santo, é revivificada - daí a "festa" - e, porque ciente de sua identidade, é também hábil para escrever a sua própria história.

Como pode ser visto, atravessar o período da gravana é como com a licença da cabo-verdiana Fátima Bettencourt - "semear em pó", numa terra que, apesar de regada a suor ou lágrima, ainda assim é capaz de germinar a semente, transformá-la numa pequena muda e, mais tarde, num ancestral imbondeiro que representa não só as vozes de Alda Espírito Santo e Conceição Lima, mas de todas as mulheres são-tomenses.

Referências bibliográficas:

HOLANDA, Lourival. Sob o signo do silêncio: Vidas secas e O estrangeiro. São Paulo: EDUSP, 1992, p. 17

LABAN, Michel. São Tomé e Príncipe - encontro com escritores. Porto: Fundação Eng. António de Almeida, 2002, p. 75.

LIMA, Conceição. O útero da casa. Lisboa: Editorial Caminho, 2004, p. 50-51.

SANTO, Alda Espírito. É nosso o solo sagrado da terra. Lisboa: Ulmeiro, 1978, p. 81-85. 